\title{
Potential Sustainable Cement Free Limecrete Based on GGBS \& Hydrated Lime as an Alternative for Standardised Prescribed Concrete Applications
}

ISSN: 2576-8840

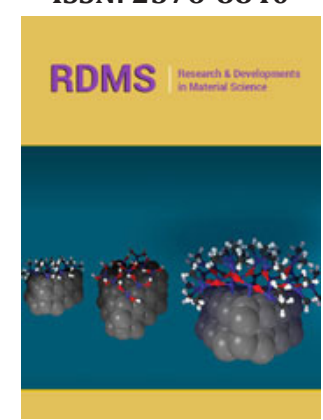

*Corresponding author: Ash Ahmed, Associate Professor, Civil Engineering Group, School of Built Environment \& Engineering, Leeds Beckett University, UK

Submission: 眥 October 01, 2021

Published: 海October 14, 2021

Volume 15 - Issue 5

How to cite this article: Joshua Cunliffe, Hafiz Muhammad Nadir, Ash Ahmed, Colin Yates, Lee Yates, et al., Potential Sustainable Cement Free Limecrete Based on GGBS \& Hydrated Lime as an Alternative for Standardised Prescribed Concrete Applications. Res Dev Material Sci. 15(5). RDMS.000874. 2021.

DOI: 10.31031/RDMS.2021.15.000874

Copyright@ Ash Ahmed. This article is distributed under the terms of the Creative Commons Attribution 4.0 International License, which permits unrestricted use and redistribution provided that the original author and source are credited.
Joshua Cunliffe ${ }^{1}$, Hafiz Muhammad Nadir ${ }^{1}$, Ash Ahmed ${ }^{2 *}$, Colin Yates $^{3}$, Lee Yates $^{3}$, Neshe Limbu ${ }^{1}$, Osama Abdelwahab ${ }^{1}$, Abdu Aljahed ${ }^{1}$ and Nayan Patel ${ }^{1}$

${ }^{1}$ Researcher, Civil Engineering Group, School of Built Environment \& Engineering, Leeds Beckett University, UK

${ }^{2}$ Associate Professor, Civil Engineering Group, School of Built Environment \& Engineering, Leeds Beckett University, UK

${ }^{3}$ Conserv Lime Products, UK

\section{Abstract}

A fundamental issue with the active ingredient of concrete, Portland cement, is its energy-intensive manufacturing process, which has led to the cement industry emitting up to $10 \%$ of global CO2 levels. To facilitate the reduction in the embodied $\mathrm{CO}_{2}$ of concrete, the Portland Cement (PC) content has been entirely replaced volumetrically with Hydrated Lime (HL) and ground granulated blast furnace slag (GGBS or SL). GGBS was used to replace hydrated lime content in 10\% increments up to $100 \%$ GGBS. Analysis of compressive and flexural strength and density testing was performed on samples to investigate the mechanical and physical properties at 7,28 and 91-day curing ages, whilst flexural testing was conducted at 91 days curing age. Four standard mix ratios, 1:1:3, 1:2:3, 1:1:2 and 2:1 was made for comparison. Two curing conditions were tested at 91-day curing age, these being air-cured and water curing. Results have shown the optimum mix ratio to be 1:1:2 for all mixes. The optimum mix being HL 1:1:2 SL80\%, water cured exceeding 25MPa. Throughout the different ratios, it can be concluded that the optimum replacement of GGBS lies between $80-90 \%$; it can also be noted that $100 \%$ GGBS content sees a significant drop in compressive and flexural strength, indicating the presence of hydrated lime to be a catalyst for strength gain.

\section{Introduction and Background}

Portland Cement (PC) is the key ingredient used in concrete; mixed with its other constituents, aggregates and water, a chemical reaction occurs, resulting in calcium silicate hydrate (C-S-H) gel production, which strongly binds the constituents through a chemical process known as hydration. This hydration process continues with time, and at the 28day point, concrete produced with PC has reached approximately 99\% of its mechanical properties, mainly compressive and tensile strength [1].

PC can be manufactured in various forms. A range of raw materials are used in PC production; these are typically calcareous materials such as limestone and shale and clays are normally used. The chemical compounds contained in the raw materials are crucial to the quality of the cement. The chemical composition of the PC is dependent on the raw materials used; predominantly, compounds of lime $(\mathrm{CaO})$ are present along with silicon dioxide $\left(\mathrm{SiO}_{2}\right)$ and alumina $\left(\mathrm{Al}_{2} \mathrm{O}_{3}\right)$. The lime content is sourced from the use of limestone, whilst the silica and alumina content are obtained from the use of argillaceous materials such as clay [2]. PC 
is typically divided into five classifications; CEM I, CEM II, CEM II, CEM IV and CEM V. CEM I being 95-100\% PC blend, whereas CEM $\mathrm{V}$ or composite cement contains various other constituents such as GGBS, Silica Fume (SF), Pulverised Fuel Ash (PFA) and another natural pozzolana [3].

Due to its desirable properties for civil engineering purposes, concrete is the most consumed material on the planet behind water; however, the vast consumption of PC has created a growing environmental issue [4]. The manufacturing process of PC is an energy-intensive process that leads to the high amounts of embodied carbon dioxide associated with PC. Approximately four billion tonnes of PC are manufactured annually, with this expected to rise to approximately 5.5 billion tonnes by the year 2050; it is already estimated that PC production contributes up to $10 \%$ of global carbon emissions [5]. In comparison, the aviation industry accounts for only $3 \%[6]$.

Table 1 displays the embodied $\mathrm{CO}_{2}$ associated with some commonly used Partial Cement Replacements (PCR). It can be seen that for one tonne of $\mathrm{PC}$, nearly an equivalent tonne of $\mathrm{CO}_{2}$ is produced [7]. It can be determined that by reducing PC use in concrete, the embodied $\mathrm{CO}_{2}$ can be drastically reduced.

Table 1: Embodied $\mathrm{CO}_{2}$ of cement replacement materials [6].

\begin{tabular}{|c|c|}
\hline Material & Embodied $\mathrm{CO}_{\mathbf{2}} \mathbf{( K g} /$ tonne $)$ \\
\hline PC/CEM I & 930 \\
\hline GGBS & 52 \\
\hline PFA & 4 \\
\hline Limestone & 32 \\
\hline Minor addition constituent & 32 \\
\hline
\end{tabular}

\section{Replacement materials and properties}

Direct and partial cementitious replacements can be classified in two ways; pozzolans or industrial by-products. Pozzolans are fine powdered material that is chemically rich in siliceous and aluminous compounds. These silica and alumina compounds react with calcium hydroxide and alkalis in the hydration process, allowing additional C-S-H gel to be produced beyond the 28-day curing age. This is why when the addition of pozzolana is used, the development of properties of concrete may continue to 91 days curing age, but research has shown it can continue to 365 days, although the effects beyond 91 days are minimal [6]. Ultimately the addition of pozzolana can lead to enhanced properties of concrete [8].

GGBS is an industrial by-product of the iron and steel industry; waste slag from the blast furnace is removed and, once hardened, it is ground into a fine powder to produce GGBS. GGBS has already been used and is a well-established PCR when used with PC. It is chemically similar to $\mathrm{PC}$ and is not a pozzolan.

Due to GGBS being chemically similar to that of PC (Table 2); [9], it behaves similarly and can therefore replace PC up to high percentages, typically $30-70 \%$ replacement range, although up to $90 \%$ cement replacement is possible. However, GGBS requires calcium hydroxide to gain strength during hydration and therefore requires another cementitious constituent high in calcium hydroxide to reach higher mechanical strengths. PC-based concrete creates C-S-H when it reacts with water; it also produces $\mathrm{Ca}(\mathrm{OH})_{2}$, which in the case of PC concrete, is an unwanted by-product that does not contribute to the concrete's mechanical properties, in fact it can facilitate the corrosion process [6]. When GGBS is used to replace PC content, the GGBS reacts with $\mathrm{Ca}(\mathrm{OH})_{2}$ and produces additional C-S-H, making the presence of $\mathrm{Ca}(\mathrm{OH})_{2}$ essential in the mix; for this research, the $\mathrm{Ca}(\mathrm{OH})_{2}$ content will be present in the form of CL-90 hydrated lime content [10].

Table 2: Chemical composition of GGBS compared with PC [9].

\begin{tabular}{|c|c|c|}
\hline $\begin{array}{c}\text { Chemical } \\
\text { Constituent }\end{array}$ & $\begin{array}{c}\text { Percentage by Mass } \\
\text { (\%) GGBS }\end{array}$ & $\begin{array}{c}\text { Percentage by Mass } \\
\text { (\%) PC }\end{array}$ \\
\hline $\mathrm{SiO}_{2}$ & 35.3 & 18.8 \\
\hline $\mathrm{Fe}_{2} \mathrm{O}_{3}$ & 13.2 & 3.3 \\
\hline $\mathrm{Al}_{2} \mathrm{O}_{3}$ & 14.1 & 5 \\
\hline $\mathrm{CaO}$ & 40 & 63.3 \\
\hline $\mathrm{MgO}$ & 8.2 & 1.5 \\
\hline
\end{tabular}

GGBS use also has benefits on the properties of concrete. The durability of concrete benefits from the addition of GGBS in the mixture; two types of sulphate attacks (ettringite and thaumasite) are significantly reduced as GGBS reduces the permeability of concrete; furthermore, GGBS addition also improves chloride attack resistance which is beneficial when used in reinforced concrete as the steel rebar have further protection. A study by Higgins and Crammon (2010) found that concrete made with 70\% GGBS and 30\% PC performed well against thaumasite attack in various solutions in which it was exposed [11].

The material lime is also considered a binder in construction materials; it is obtained from sedimentary rock types such as dolomite, aragonite, and chalk, as these rocks contain a minimum chemical composition of $50 \%$ calcium carbonate. Similarly, to cement, lime must be extracted from the ground and processed. It is ground down into small fragments and processed through a lime kiln, where the raw limestone breaks down into two products, calcium oxide (quicklime) and $\mathrm{CO}_{2}$. The quicklime is then crushed down again at this point; the quicklime can be added to water, causing a chemical reaction, resulting in $\left(\mathrm{Ca}(\mathrm{OH})_{2}\right)$, also known as 
slaked lime. Alternatively, it can further ground to produce a fine powder known as ground quicklime [12]. There are in general three types of lime used in construction and civil engineering applications: hydrated (CL-90), hydraulic and non-hydraulic (lime putty). Hydrated lime, also known as slaked lime, is a form of quicklime where a small percentage of water content is added so that there is a slight chemical reaction between the quicklime and water. This process is sometimes referred to as lime quenching; the lime is safer to handle than quicklime, which is highly alkali and caustic, making it dangerous to handle [13]. Hydraulic lime contains a slight variation in the raw materials used in manufacturing. Unlike hydrated lime, hydraulic lime uses limestone, which contains amorphous silica, although this can also be induced into the raw materials. This variation in chemical constituents means that the hydraulic lime contains dicalcium silicate (like cement) therefore, will set with the addition of/reaction with water. Another lime product, lime-putty, also known as non-hydraulic, will not set in water and will predominantly set through the carbonation process as illustrated in Figure 1; [13]. In this paper, the CL-90 hydrated lime has been used.

\section{THE LIME CYCLE}

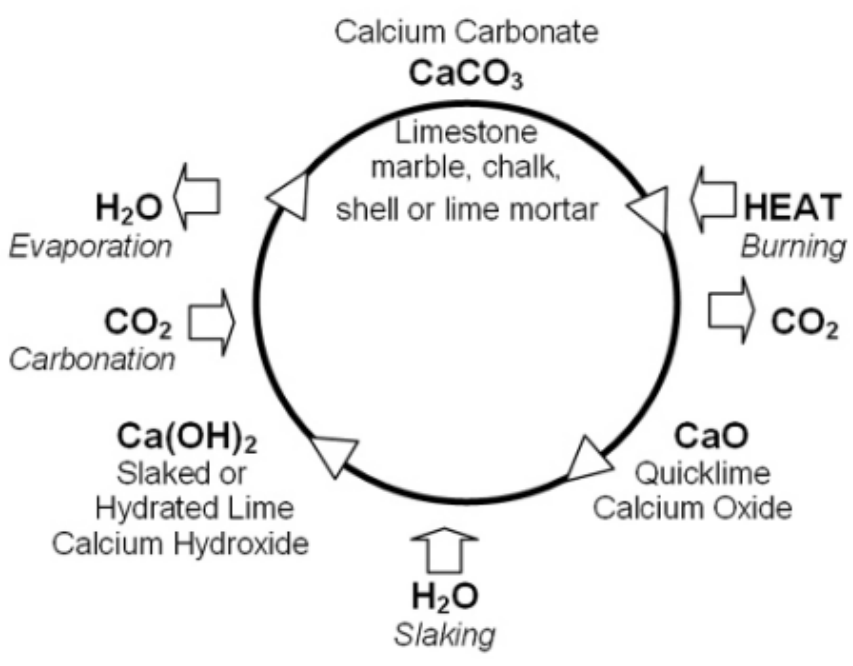

Figure 1: Production and re absorption of $\mathrm{CO}_{2}$ through carbonation [12].

Lime has commonly been used in modern applications for mortars and renders but has not seen excessive use in structural materials since Portland Cement (PC) was implemented in the $19^{\text {th }}$ century. The critical issue with cement production is that to obtain PC, it must be heated over $1200{ }^{\circ} \mathrm{C}$ for several hours in a rotary kiln. To achieve these temperatures for long durations of time, vast amounts of energy are required. Due to this issue, a study has been conducted to analyse the effect on concrete's (limecrete) physical and mechanic properties with zero PC content, instead, using a binary blend of CL-90 and GGBS, thus significantly reducing the embodied $\mathrm{CO}_{2}$ associated with the material. Furthermore, the CL-90 content further benefits from an environmental perspective as the carbonation process further reduces $\mathrm{CO}_{2}$ from the atmosphere over time. This research aimed to provide an alternative material to conventional concrete specifically for low load domestic applications and low load structural applications based on the findings. In doing so, a reduction of embodied $\mathrm{CO}_{2}$ can be observed, making the limerete used significantly more environmentally friendly than PC based concrete. BS 8500 outlines the classification for standardised and general-purpose concrete of characteristic compressive strengths from 7.5MPa-25MPa, with applications ranging from kerb bedding and blinding up to reinforced flooring and slabs for concrete achieving ST5. Table 3 shows ST1-ST5 classifications and the wide range of applications for the intended characteristic compressive strengths of concrete designed in this research. The ST5 classification contains some applications for moderate structural purposes and the addition of steel reinforcement. The material researched for this study is expected to replace PC concrete in applications where loads do not exceed 25MPa, such as domestic flooring and foundations, blinding, kerbing, and any other low load applications. Compressive strengths of $25 \mathrm{MPa}$ or more may also be considered for moderate reinforcement and structural applications. 
Table 3: BS 8500 Standardised prescribed concrete/General purpose concrete compressive strength classifications [6].

\begin{tabular}{|c|c|c|}
\hline Classification & Strength at 28-Days (MPa) & Applications \\
\hline ST1/GEN0 & 7.5 & Kerb bedding, backing, drainage works, haunching and blinding. \\
\hline ST2/GEN1 & 10 & $\begin{array}{c}\text { Un-reinforced strip footings, trench fill foundations, drainage works, blinding house floors, pad } \\
\text { foundations, non-structural mass concrete (DC-1). }\end{array}$ \\
\hline ST3/GEN2 & 15 & foundations for large walls, garages, houses and extensions, unreinforced bases \\
\hline ST4/GEN3 & 20 & $\begin{array}{c}\text { Garage floors (not designed as suspended and un-reinforced) shed and workshop bases, internal } \\
\text { floor slabs (un-reinforced). }\end{array}$ \\
\hline ST5 & 25 & $\begin{array}{c}\text { Foundations for environmental barrier post and planted lighting columns, foundations for traffic } \\
\text { signposts, reinforced ground floor house and garage slabs, either ground bearing, suspended or } \\
\text { over sub-floor voids. }\end{array}$ \\
\hline
\end{tabular}

\section{Experimental}

According to the usual mix ratios used in concrete technology and the masonry field, the binder, sand, and gravel ratio was based as shown in Table 4. The amount of binder content in the mixes (100\% lime, lime + slag, or $100 \%$ slag) varied from $17-33 \%$. For each mix ratio of limecrete, the amount of slag replaced lime at the following weight $\%: 0,10,20,30,40,50,60,70,80,90 \& 100$; therefore, 40 mixes in total given there were 4 different ratios. The $0 \%$ replacement, also referred to as the 'control specimen' was used as the reference to which the performance of all replacements was measured. The mixes have been selected to show the differing quality of materials available and the impact this has on the properties of the fresh and hardened limecrete. As lime behaves in a different way to cement, i.e. it has superior workability, in contrast to concrete preparation, the water/binder ratio was kept to 0.5 to obtain an S1 slump. X-ray diffraction analysis was conducted to ascertain the chemical composition of the binder materials (lime \& slag). The lime was locally sourced hydrated lime (CL-90 grade), and the slag was also produced in the UK. The compressive strengths were evaluated at 7, 28, and 91 days. In addition, the flexural strength was determined at 91 days. All preparation and testing were conducted in accordance with the relevant European British standards-BS EN [14-21]. Compressive strength was determined using $100 \mathrm{~mm}$ cubes. To ensure repeatability, a total of three cubes were cast for each testing age, and the characteristic compressive strength was reported [21]. The cubes were tested by using an Avery-Denison testing machine at a loading rate of 200N/ min, Figure 2. Three cubes from each mix were tested, with the average load being recorded. For flexural strength, the limecrete prisms were tested using a centre point method to determine its flexural strength. The prism was subjected to a three-point bending moment by applying the load through the rollers, Figure 3. The maximum load is recorded, and flexural strength is then calculated. The testing was carried out in accordance with BS EN12390:5.

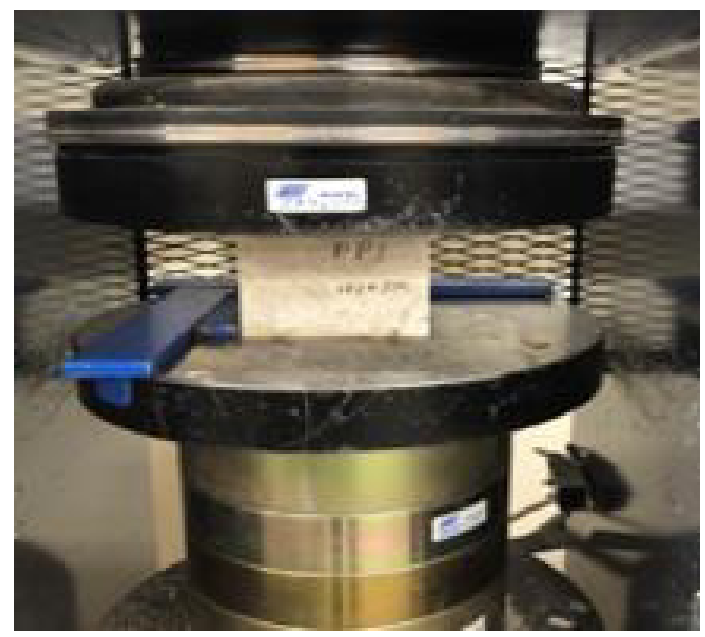

Figure 2: Compressive testing of cubes.

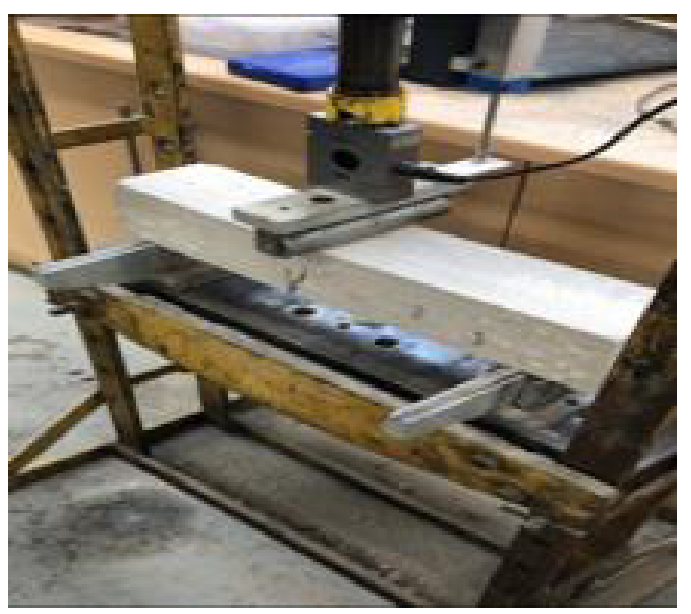

Figure 3: Flexural testing of prisms. 
Table 4: Limecrete specimen mixes prepared.

\begin{tabular}{|c|c|c|c|}
\hline Mix Ratio Binder:Sand:Gravel & Binder Content \% (Lime + GGBS) & Mix Name & GGBS Content (\%) Replacement for CL-90 \\
\hline $1: 1: 3$ & 20 & HL $1-1-3$ & $0,10,20,30,40,50,60,70,80,90 \& 100$ \\
\hline $1: 2: 3$ & 17 & HL $1-2-3$ & $0,10,20,30,40,50,60,70,80,90 \& 100$ \\
\hline $1: 1: 2$ & 25 & HL $1-1-2$ & $0,10,20,30,40,50,60,70,80,90 \& 100$ \\
\hline $1: 2^{*}$ & 33 & HL $2: 1^{*}$ & $0,10,20,30,40,50,60,70,80,90 \& 100$ \\
\hline
\end{tabular}

* Represents 2 parts total aggregate (coarse $\&$ fine) to 1 part binder - normally referred to 2:1 ratio in the masonry field.

\section{Results}

The $100 \times 100 \mathrm{~mm}$ air-cured cubes have been tested on 7 days, 28 days and 91 days of hydration for all mixes of SL under the compressive testing machine. The cubes of SL mixes were also cured in water for 91 days and tested for compressive strength to assess any improvement with curing. The compressive strength has been calculated using the following formula:

$\sigma_{c}=P / A$

Where $\sigma_{c}$ is compressive strength,

' $P$ ' is load in $\mathrm{kN}$, and ' $A$ ' is the area of the cube in $\mathrm{mm}^{2}$

The $100 \times 100 \times 500 \mathrm{~mm}$ prisms of all the mixes were tested at 91 days after on a three-point loading machine. The flexural strength of prisms has been calculated using the following formula:

$\sigma_{f}=\frac{3 P L}{2 B D^{2}}$
Where $\sigma_{\mathrm{f}}$ is flexural strength,

' $P$ ' is load in $\mathrm{kN}$, and ' $L$ ' is the length of the prism (500mm), ' $B$ ' is the width of the prism $(100 \mathrm{~mm})$, and ' $D$ ' is the depth of prism $(100 \mathrm{~mm})$.

The x-ray spectrometry/ diffraction tests were conducted to determine elemental analysis and composition of GGBS (SL) and hydrated lime $\mathrm{Ca}(\mathrm{OH})_{2}$, as shown in Table 5. GGBS contains more than $70 \%$ oxides of metals, including $40 \%$ silicates, $44 \%$ Calcium oxide and $11 \%$ alumina, which propose it as an excellent supplementary cementitious material (SCM) as per the conditions prescribed by ASTM standards [22]. The composition of hydrated lime shows that it contains more than $93 \%$ of $\mathrm{Ca}(\mathrm{OH})_{2}$, which is essentially required to react with silicates in GGBS to form C-S-H gel in pozzolans - lime reaction for enhancement of binding strength.

\section{Compressive strength of SL mixes}

\section{HL SL 1-1-2 Compressive Strength}

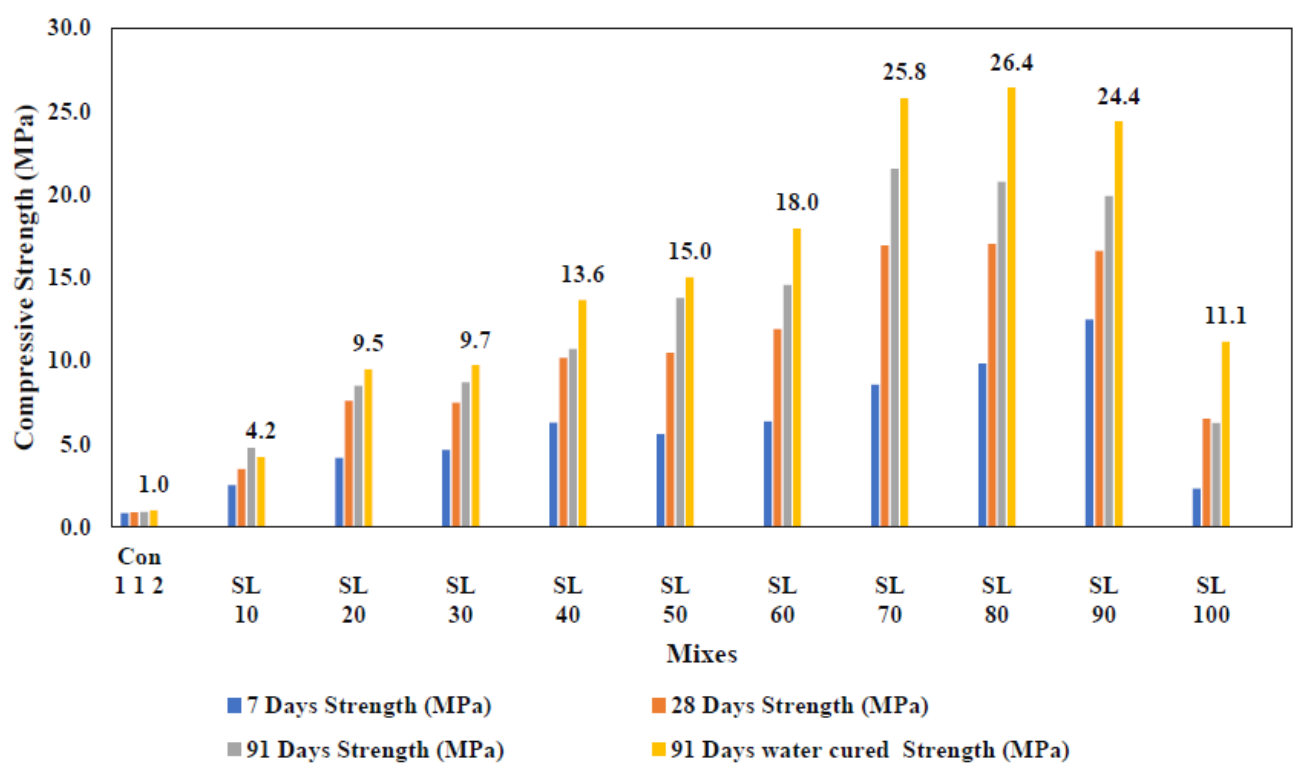

Figure 4: Compressive strength of HL SL 1-1-2 at 7, 28 and 91 days. 
Figures 4-7 display the characteristic compressive strengths of CL-90 (HL) with the addition of GGBS (SL) in 10\% increments up to $100 \%$ GGBS content. All mix ratios of HL SL managed to exceed $20 \mathrm{MPa}$ at some replacement percentage primarily between 60 and $90 \%$, in addition to this several mix designs were achieved beyond $25 \mathrm{MPa}$, with the addition of water curing. The optimum mix design for HL SL was HL 1-1-2 SL80 (20\% CL-90, 80\% slag) water cured, which achieved a 91-day compressive strength of over 26MPa. The optimum GGBS content can be noted as being within the range of SL80-SL90 (80\%-90\%) for ratios 1-1-3, 1-2-3 and 2-1 whereas for mix ratio 1-1-2 the optimum range lies between SL70-SL80 (70\%-80\%). Another key point to take from the data is that for all mix ratios, SL100 designs (100\% slag, 0\% CL-90) see a significant decrease in strength when compared to the overall trend. For the most part, a somewhat linear increase can be observed up until SL90, after this point the compressive and flexural strength decrease significantly. As for these mix designs, there is 0\% CL-90 content, it can be determined that the CL-90 hydrated lime is a catalyst and is crucial to the mechanical properties of the mix design. The SLlime composites with $20-90 \%$ SL showed significant strengths at par with standard prescribed cement concrete ST1-ST5 (7.5-25 MPA strength) and designated general-purpose cement concrete Gen0-Gen3 (7.5-20MPa strength) [23]. Thus, there is potential for applications in these areas as a more sustainable and cement free alternative for conventional concrete.

\section{HL SL 1-1-3 Compressive Strength}

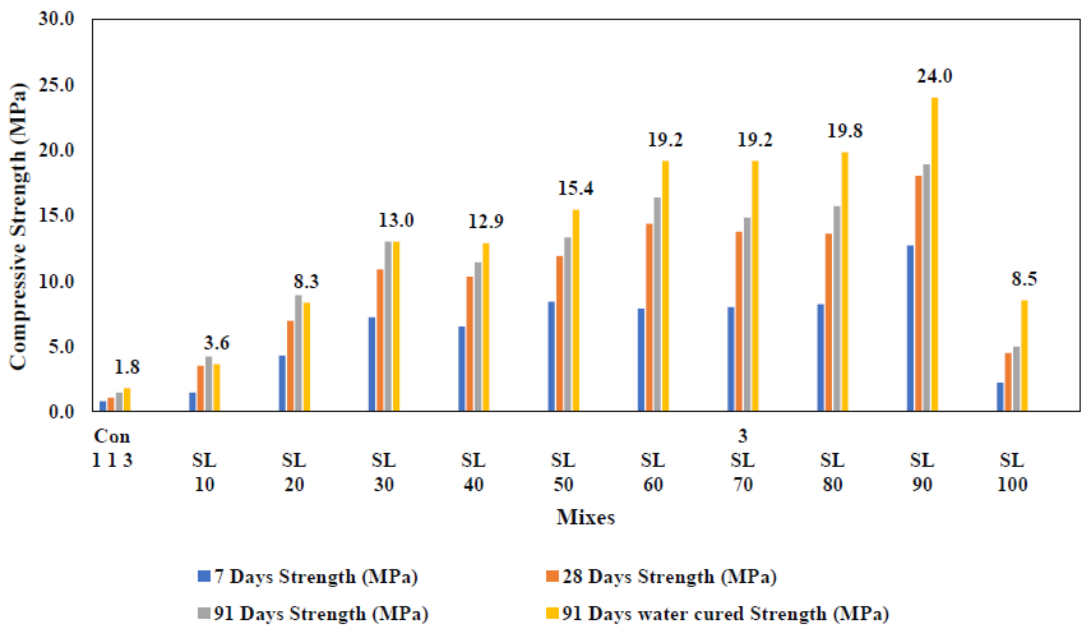

Figure 5: Compressive strength of HL SL 1-1-3 at 7, 28 and 91 days.

\section{HL SL 2-1 Compressive Strength}

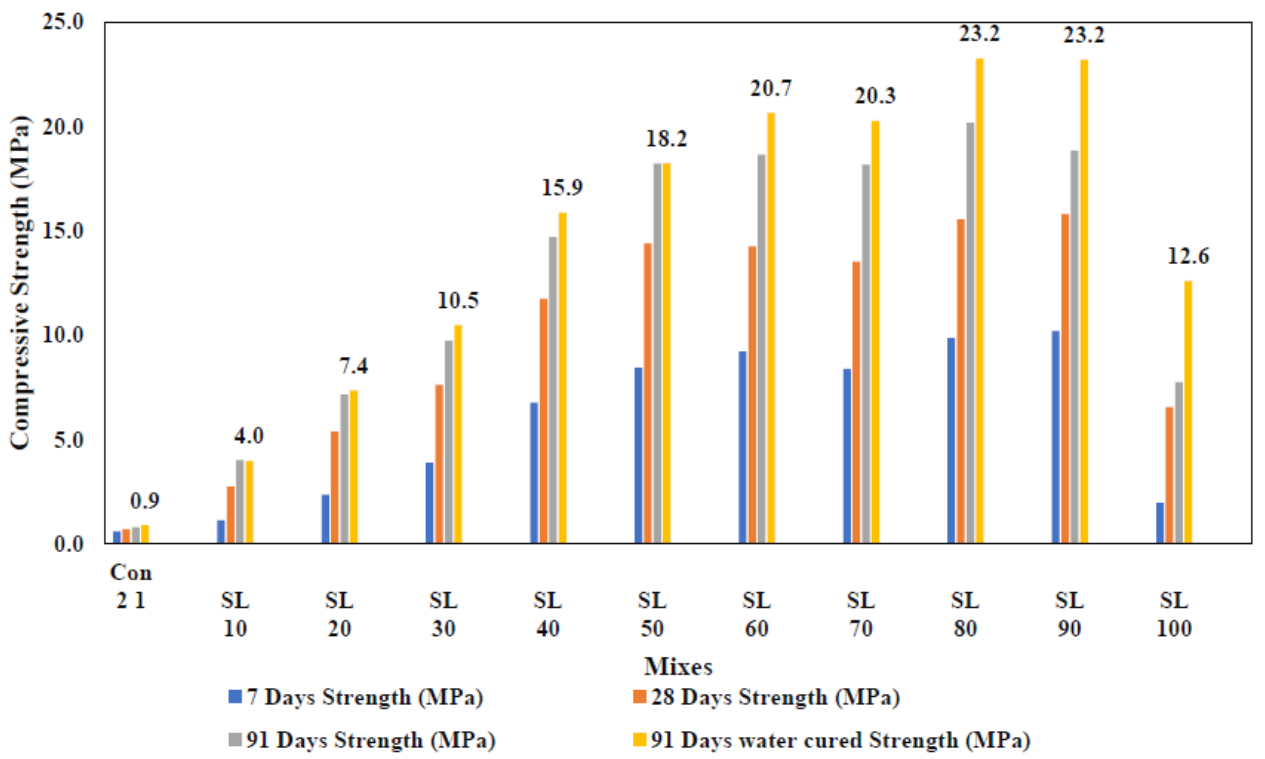

Figure 6: Compressive strength of HL SL 2-1 at 7,28 and 91 days. 
HL 1-2-3 Compressive strength

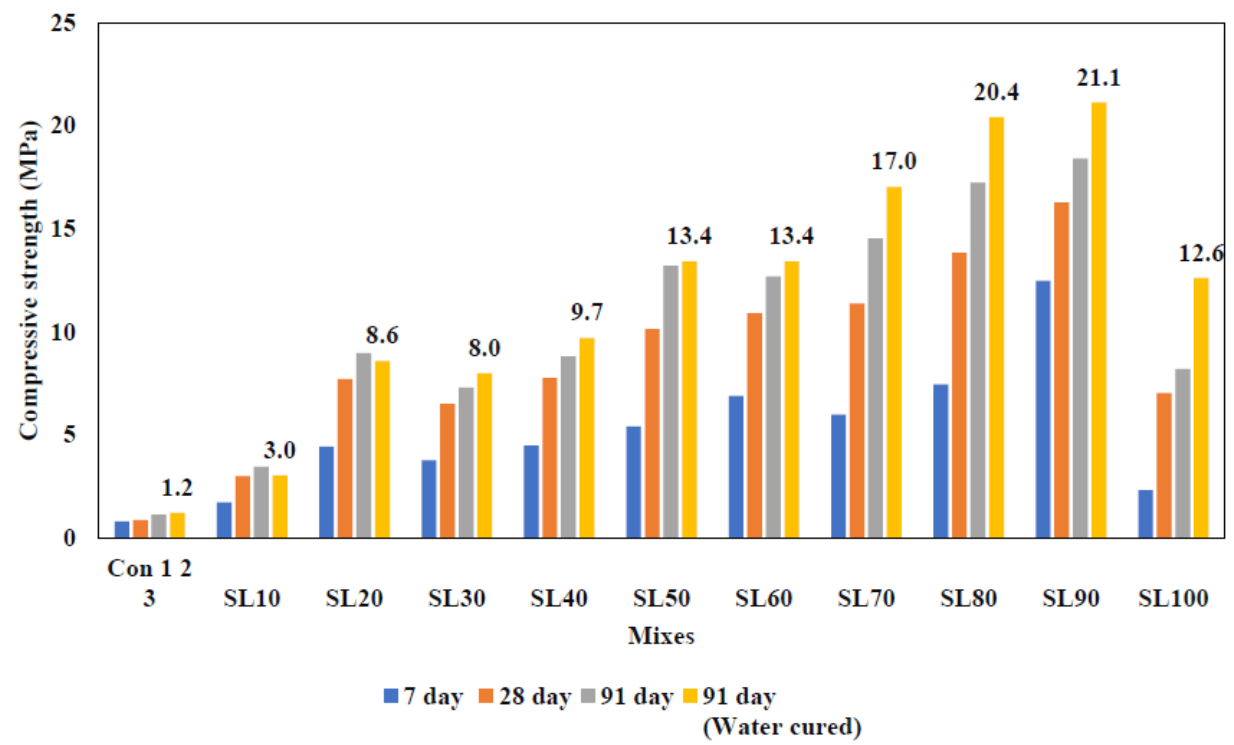

Figure 7: Compressive strength of HL SL 1-2-3 at 7, 28 and 91 days.

Table 5: Elemental analysis of GGBS and hydrated lime using x-ray spectrometry/ diffraction tests.

\begin{tabular}{|c|c|c|}
\hline Composition & GGBS (\%) & Hydrated Lime $\mathrm{Ca}(\mathrm{OH})_{2}(\%)$ \\
\hline $\mathrm{Fe}_{2} \mathrm{O}_{3}$ & 0.31 & $<0.1$ \\
\hline $\mathrm{SiO}_{2}$ & 39.4 & 2.22 \\
\hline $\mathrm{TiO}_{2}$ & 0.47 & 0.20 \\
\hline $\mathrm{CaO} / \mathrm{Ca}(\mathrm{OH})_{2}$ & $44.7(\mathrm{CaO})$ & $93.6\left(\mathrm{Ca}(\mathrm{OH})_{2}\right)$ \\
\hline $\mathrm{K}_{2} 0$ & 0.43 & 0.27 \\
\hline $\mathrm{Al}_{2} \mathrm{O}_{3}$ & 11.1 & 1.91 \\
\hline Mg0 & 1.46 & 0.97 \\
\hline $\mathrm{Na}_{2} \mathrm{O}$ & 0.11 & 0.25 \\
\hline $\mathrm{P}_{2} \mathrm{O}_{5}$ & $<0.1$ & $<0.1$ \\
\hline $\mathrm{C}_{1}$ & $<0.1$ & $<0.1$ \\
\hline $\mathrm{SO}_{3}$ & 1.49 & 0.11 \\
\hline
\end{tabular}

\section{Flexural strength}

The flexural strength of all the SL mixes/ ratios exceeded the $100 \%$ CL-90 control mixes. However, some of the prisms ruptured upon initial loading giving insignificant values, as shown in Figure 8. Some SL mixes performed at par with the flexural strength of high strength plain cement concrete prisms (3MPa +) [24].

Figures 9-12 shows the flexural strengths of CL-90 and GGBS concrete. The Prisms of 4 ratios of SL mixes with hydrated lime 1:1:2, $1: 1: 3,1: 2: 3$ and $2: 1$ with $10-100 \%$ of SL were tested at 91 days. All the mixes showed improvement of flexural strength as compared to the control mix. The ratio 1:1:2 with 70\% SL mix exhibited flexural strength of 3.5MPa on 91 days which is at par with a flexural strength of high-grade cement concrete, as shown in Figure 9. The ratio 1:1:3 with 90\% SL mix exhibited a strength of $2.8 \mathrm{MPa}$ on 91 days, as shown in Figure 10. The ratio 1:2:3 with a $90 \%$ SL mix exhibited a flexural strength of 3.3MPa on 91 days (Figure 11). The ratio 2:1 with $60 \%$ SL mix exhibited maximum flexural strength of 3.5MPa on 91 days (Figure 12). 


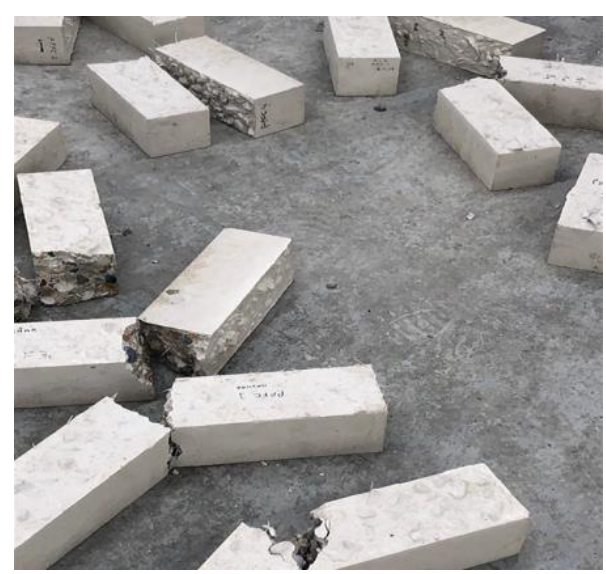

Figure 8: Ruptured prisms after 3-point loading.

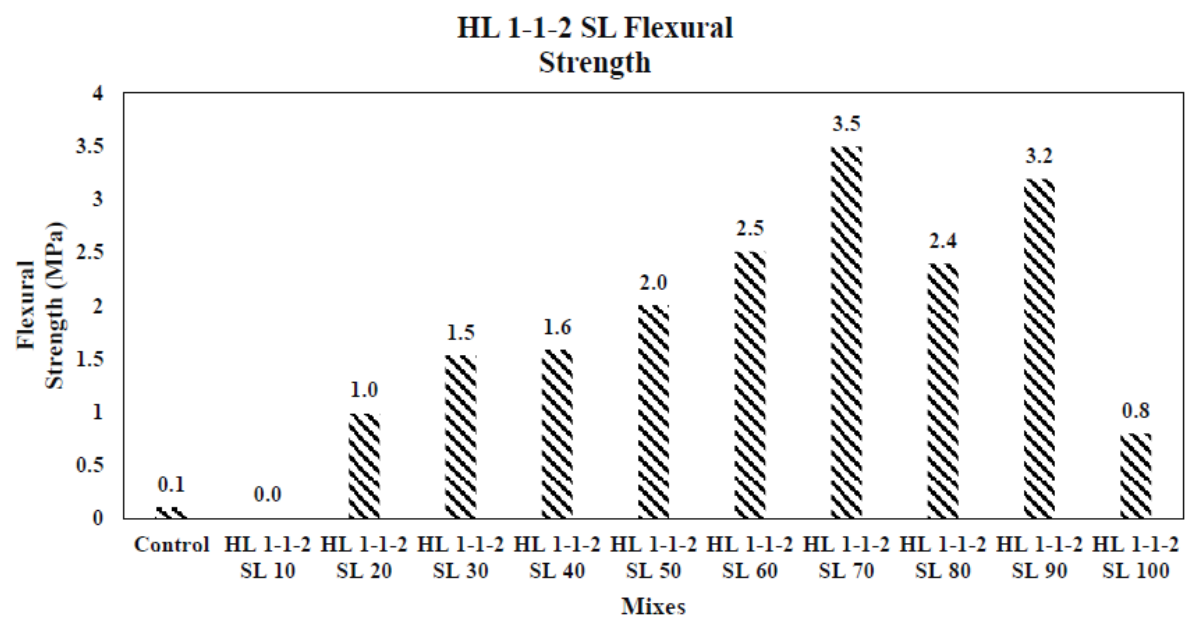

Figure 9: Flexural strength of HL SL 1-1-2.

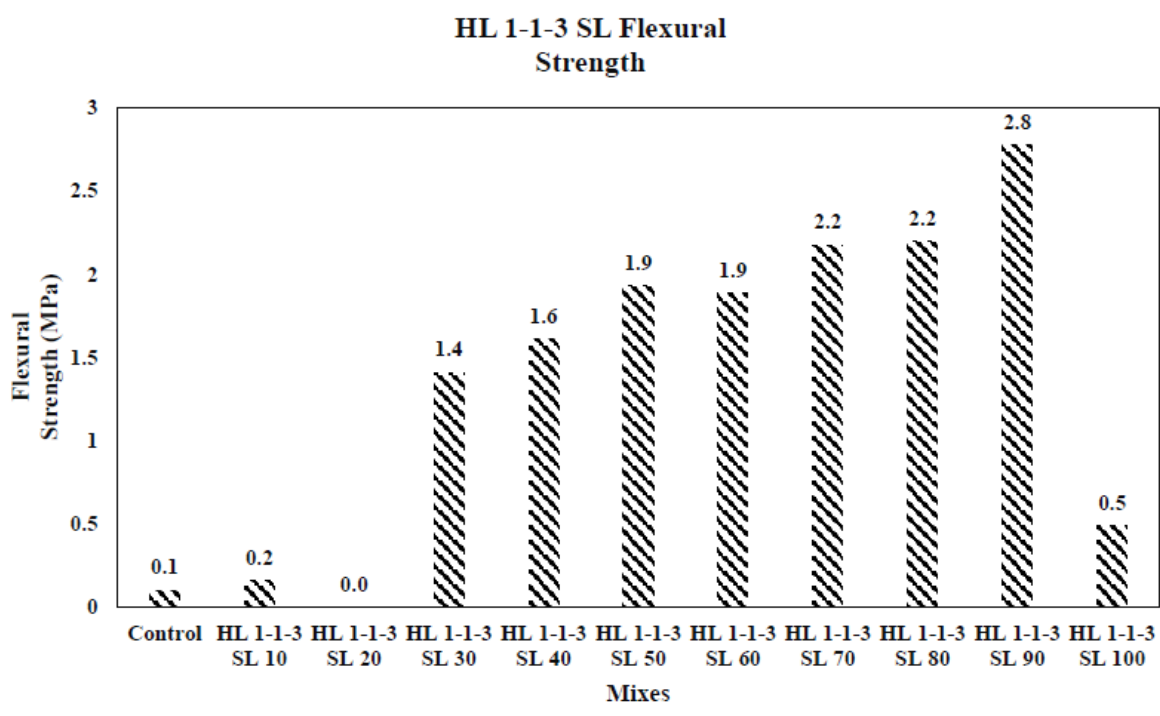

Control HL 1-1-3 HL 1-1-3 HL 1-1-3 HL 1-1-3 HL 1-1-3 HL 1-1-3 HL 1-1-3 HL 1-1-3 HL 1-1-3 HL 1-1-3

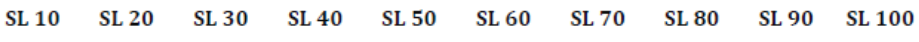

Figure 10: Flexural strength of HL SL 1-1-3. 
HL 1-2-3 SL Flexural Strength

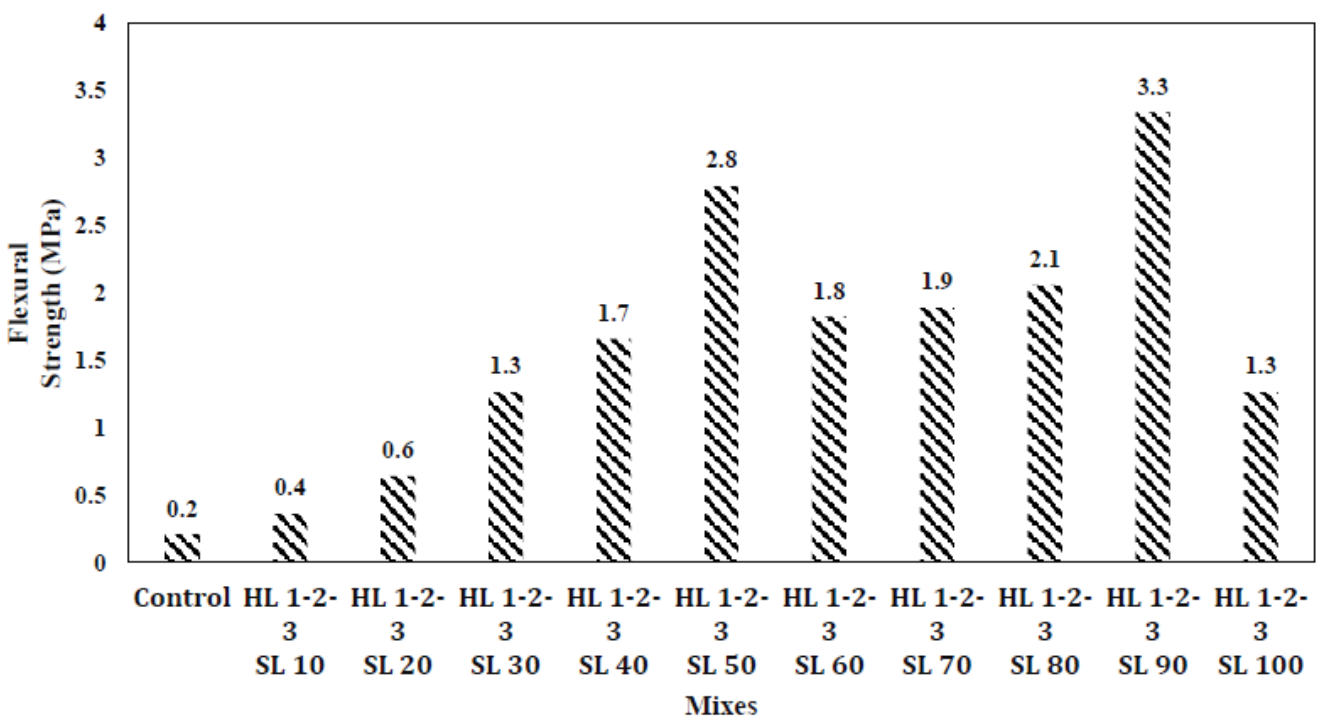

Figure 11: Flexural strength of HL SL 1-2-3.

HL 2-1 SL Flexural Strength

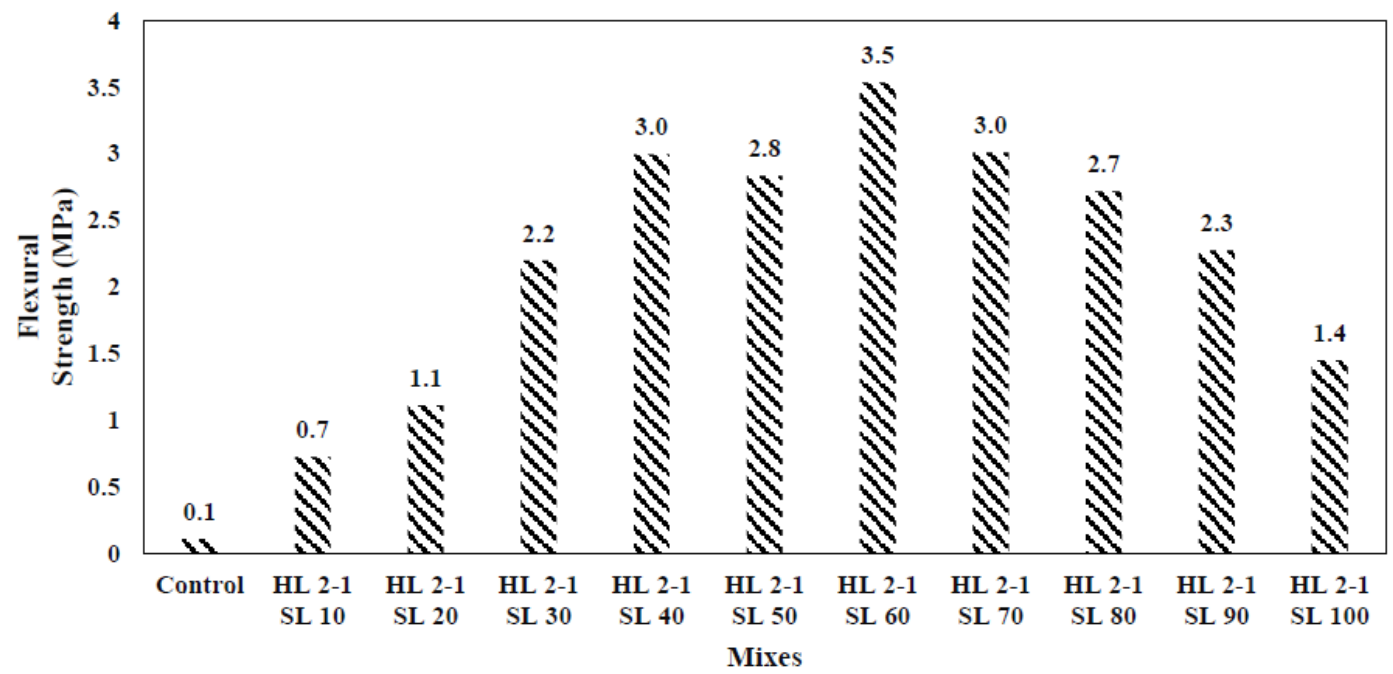

Figure 12: Flexural strength of HL SL 2-1.

\section{Improvement in compressive strength after water curing}

The cubes for all the SL mixes with hydrated lime 1:1:2, 1:1:3, 1:2:3 and $2: 1$ with $10-100 \%$ of SL were water cured for 91 days and then tested for determination/comparison with air-cured cubes. Generally, all the mixes exhibited improvement in compressive strength with water curing. An improvement of $10-80 \%$ was observed in different mixes with 78\% improvement in SL 1:1:2 100\% mix, 72\% in SL 1:1:3 100\% mix, 48\% improvement in SL
1:2:3 100\% mix and improvement of $63 \%$ was observed in SL 2:1 with $100 \%$ SL mix as shown in Figure 13. Additionally, there was a $20 \%$ improvement in strength after water curing for mixes containing $70-90 \%$ slag (10-30\% CL-90 content). These findings therefore suggest that lime mixed pozzolanic composites improve strength with curing in water over an extended period; therefore, their use in water emersed/ exposed structures is expected more beneficial as is the case in concrete. 
Percentage increase of compressive strenght of water curing against ai curing at 91 day curing age of GGBS replacement

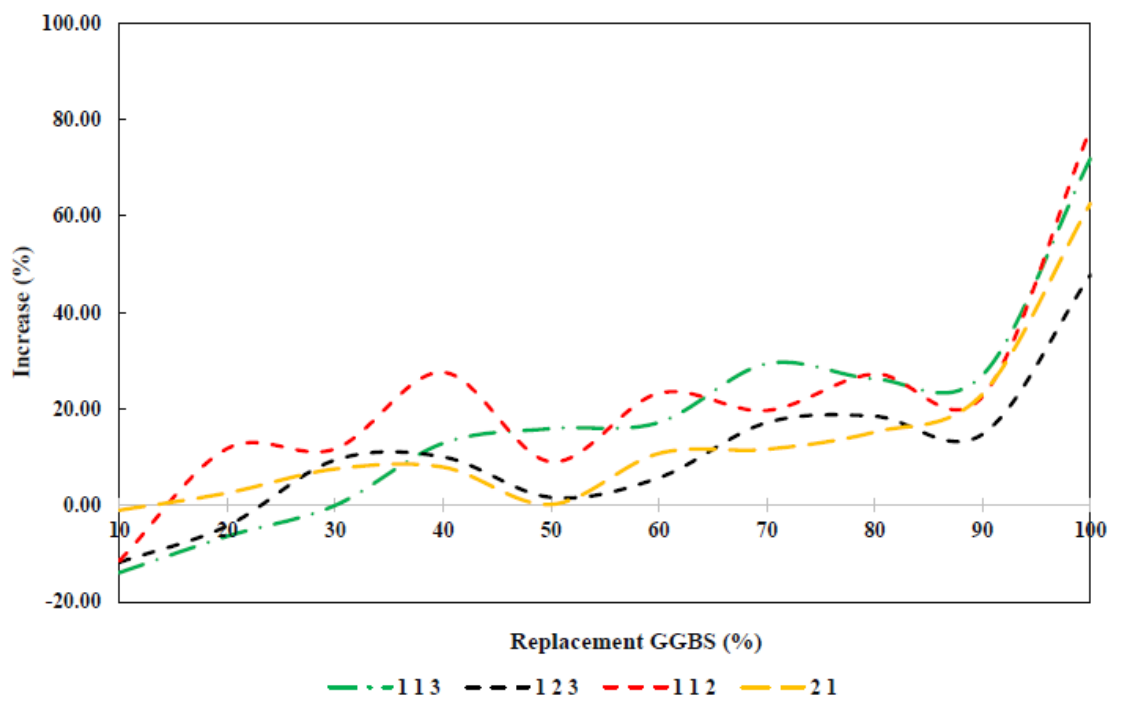

Figure 13: Comparison of air curing and water curing percentage increase at 91 days.

In addition to the analysis of results, an application of design mixes has also been included (Table 6) based on compressive strength values at 91 days. Table 6 shows that almost all CL- 90 with GGBS mixes achieved the minimum 7.5MPa at 91-day curing age. $10 \%$ GGBS content was the only mix that did not achieve ST1/GEN0 for all mix ratios. Mix ratio 1-1-2 achieved the highest compressive strength value exceeding $25 \mathrm{MPa}$ at both $70 \%$ and $80 \%$ GGBS content. Mix ratio 2-1 contained 4 mix designs that achieved ST4/ GEN3 resulting in the 2-1 ratio as having the lowest GGBS content
(60\%) to exceed 20MPa. Essentially all mixes designed with GGBS can be utilised for applications associated with Tables 3 \& 6 mainly for unreinforced domestic applications, however mixes conforming to ST4/GEN 3 and above can be used in some reinforced structural applications. Despite HL SL10 not achieving the minimum 7.5MPa, there could still be potential applications in the developing world for sustainable low-cost housing solutions as cement is an expensive commodity with an exceptionally high embodied $\mathrm{CO}_{2}$.

Table 6: Classifications of concrete tested in accordance with Standardised Concrete (ST) and General-Purpose Concrete (GEN) Compressive strengths from water cured samples have also been used during classification [23].

\begin{tabular}{|c|c|c|c|c|}
\hline \multirow{2}{*}{$\begin{array}{c}\text { Classification ST (Standardised) Series and GEN } \\
\text { (General Purpose) Series (Compressive Strength) }\end{array}$} & \multicolumn{2}{|c|}{ Mix Ratio and \% GGBS Replacement that Satisfies the Classification at 91 Days } \\
\cline { 2 - 5 } & $\mathbf{1 - 1 - 3}$ & $\mathbf{1 - 2}-\mathbf{1}$ & $\mathbf{1 - 1 - 2}$ & $\mathbf{2 - 1}$ \\
\hline ST1/GEN0 (7.5 MPa) & $20 \%-100 \%$ & $20 \%-100 \%$ & $20 \%-100 \%$ & $30 \%-100 \%$ \\
\hline ST2/GEN1 (10 MPa) & $30 \%-90 \%$ & $50 \%-100 \%$ & $40 \%-100 \%$ & $30 \%-100 \%$ \\
\hline ST3/GEN2 (15MPa) & $50 \%-90 \%$ & $70 \%-90 \%$ & $50 \%-90 \%$ & $40 \%-90 \%$ \\
\hline ST4/GEN3 (20 MPa) & $90 \%$ & $80 \%-90 \%$ & $70 \%-90 \%$ & $60 \%-90 \%$ \\
\hline ST5 (25 MPa) & - & - & $70 \%-80 \%$ & - \\
\hline
\end{tabular}

\section{Conclusion}

1. The addition of GGBS to hydrated lime improves the mechanical properties, most notably compressive strength, up to $90 \%$ GGBS replacement. Strengths of 20MPa were recorded for all ratios with replacements between 60\% and 90\% GGBS with HL SL 1-1-2 70\% and $80 \%$ exceeding $25 \mathrm{MPa}$ at 91 -day testing when water cured.
2. All mix ratios at $30 \%$ replacement satisfied the ST1/GEN0 classifications, and at least $1 \mathrm{mix}$ in each ratio satisfied up to ST4/GEN3 with 70\%-90\% 1-1-2 satisfying the maximum ST5 classification.

3. It can be determined that hydrated lime acts as a catalyst in the chemical reaction between itself and GGBS as a significant drop in compressive and flexural strength can be observed 
when using $100 \%$ GGBS content due to the reduced $\mathrm{Ca}(\mathrm{OH})_{2}$ content and, therefore prevention of further CSH development.

4. Mix ratio 1-1-2, binder content $25 \%$, was the optimum mix ratio throughout the research.

5. Water curing results in increased compressive strength, with a clear trend determining the higher percentage replacement, the higher percentage increase in compressive strength between air-cured and water cured samples.

\section{References}

1. The Constructor (2021) Why do we test concrete compressive strength after 28 days?.

2. https://www.britannica.com/technology/cement-building-material/ History-of-cement\#ref76638

3. BSI (2011) Composition, specification and conformity criteria for common cement, p. 15.

4. Gagg CR (2014) Cement and concrete as an engineering material: An historic appraisal and case study analysis. Engineering Failure Analysis 40: $114-140$.

5. Chatham House (2021) Making concrete change: Innovation in lowcarbon cement and concrete.

6. Ahmed A, Kamau J, Pone J, Hyndman F, Fitriani H (2019) Chemical reactions in pozzolanic concrete. Modern Approaches on Material Science 1(4): 128-133.

7. Mineral Products Association (2007) Embodied $\mathrm{CO}_{2}$ of UK Cement, additions and cementitious material. Fact Sheet 18 [Part 1], p. 8.

8. Chung DL (2017) 6- Cement- matrix composites. Carbon Composites, Buffalo, University of Buffalo, NY, USA, pp. 333-386.

9. Łukowski P, Salih A (2015) Durability of mortars containing ground granulated blast-furnace slag in acid and sulphate environment. Procedia Engineering 108: 47-54.

10. Samad S, Shah A, Limbachiya MC (2016) Strength development characteristics of concrete with blended cement using GGBS under various curing conditions. Indian Academy of Sciences.
11. Higgins DD, Crammond NJ (2003) Resistance of concrete containing ggbs to the thaumasite formof sulfate attack. Cement \& Concrete Composites 25: 921-929.

12.https://www.nordkalk.com/products/product-information/ production-process.

13. Tradtional Building (2018) Hydrated vs Hydraulic lime.

14. BSI (2000) Part 1: Composition, specifications, and conformity criteria for common cement. British Standards Institution (BSI), London, UK.

15. BSI (2012) Testing hardened concrete-part 1: Shape, dimensions and other requirements for specimens and moulds. British Standard Institution, London, UK, 2012.

16. BSI (2009) Testing hardened concrete-part 2: Making and curing specimens for strength tests. European Committee for Standardization, Brussels, Belgium.

17. BSI (2000) Testing hardened concrete-part 4: Compressive strength specification for testing machines. British Standards Specification, London, UK.

18. BSI (2008) Eurocode 2: Design of concrete structures, EN 1992-1-1: General rules and rules for buildings. British Standards Institution and CEN European Committee for Standardization.

19. BSI (2006) BS 8500-1: Concrete-complementary British standard to BS EN 206-1-Part 1: Method of specifying and guidance for the specifier. British Standards Institution, London, UK.

20. BSI (2009) Testing hardened concrete-part 5: Flexural strength of test specimens. British Standards Institution and CEN European Committee for Standardization, London, UK.

21. Kamau J, Ahmed A, Hirst P, Kangwa J (2016) Suitability of corncob ash as a supplementary cementitious material. Int J Mater Sci Eng 4(4): 215228.

22. ASTM Committee (2019) ASTM C125-19 standard terminology relating to concrete and concrete aggregates. Annu B ASTM Stand 04(02).

23. Hansons UK (2021) Types of concrete by hanson cement group available.

24.Xu SL, Wang N, Zhang XF (2012) Flexural behaviour of plain concrete beams strengthened with ultra-high toughness cementitious composites layer. Mater Struct 45: 851-859. 